\title{
OS PRINCÍPIOS FUNDANTES NO DIREITO DAS OBRIGAÇÕES
}

João Carlos Bianco

\section{RESUMO}

A pós-modernidade submeteu o direito a uma mudança de paradigma, tal afirmativa encontra respaldo quando se analisa os princípios fundantes do direito das obrigações. O novo código preocupou-se com a efetivação dos valores sociais, éticos e operacionais, primando pela busca da justiça e da verdade material, não se contentando mais com o simples parecer do judiciário, rompendo de vez com o formalismo exegético que se experimentou outrora. O presente trabalho volta-se exatamente para o estudo dos princípios que instruíram o direito das obrigações nesse contexto.

Palavra-chave: Direito Civil. Direito das Obrigações. Princípios Fundantes.

\section{DO SISTEMA FECHADO AO SEMIABERTO}

Até pouco antes de alvorecer a metade do século passado, a fórmula casuística de legislar, denominada de regulação por fatispécie, foi fartamente utilizada nos textos normativos. Essa fase, conhecida como a 
Era da Codificação, propiciou na França, em 1804, o surgimento do CódeNapoléon, sistema fechado em que a atividade do interprete resumia-se a isolar o fato e identificá-lo à norma aplicável. Tudo se resolvia pela casuística: a subsunção do fato à lei.

Em torno dos códigos inaugurou-se a Escola da Exegese ${ }^{88}$, que debatia a respeito da literalidade dos textos legais, pautando a ideia de que nos códigos estariam as soluções para todos os fatos que o Direito se propunha a regular. Ao juiz o código. E servindo-se do código o juiz infalivelmente resolveria o caso concreto. Do código o juiz não podia afastarse, pois ele era labouche de laloi.

No curso de tal panorama jurídico foram concebidos o Código Civil do Chile de 1855, o primeiro Código Civil de Portugal de 1867, o primeiro Código Civil da Itália de 1895, o Código Civil da Alemanha de 1900, o Código Civil e o Código das Obrigações da Suíça de 1904, o primeiro Código Civil brasileiro de 1916, e outros mais, tendo o modelo francês a inspirá-los.

Com o fim da última Guerra Mundial, o mundo experimentou expressivo processo de transformações e incertezas, quando os juristas passaram a conceber a ideia de que a técnica da perfeição da lei já estava ultrapassada. A sociedade deixou de ter uma estrutura simples em que era possível ler em tábuas o que pode e não pode, o que é justo e injusto, o que é lícito e ilícito.

A atual sociedade é altamente complexa, aberta e de célere transformação, de modo que a prévia previsão dos fatos criando leis que os regulamentam torna-se tarefa legislativa inexequível. É o oportuno ensinamento do lusitano Paulo Otero:

\footnotetext{
88 A Escola da Exegese revelou significativos estudiosos do Direito, como Demolombe, Troplong, Laurent e Marcadé. O posicionamento fundamental da Escola é o de que o Direito revela-se pelas leis. Portanto, para os seus pensadores a interpretação parte unicamente do direito positivo, desnecessária a utilização de elementos que lhe são extrínsecos, como exposto no texto acima. Foi uma fase de inovações na ciência jurídica, como em matéria de sucessão a supressão do direito de primogenitura, no direito de família a admissão do divórcio em caso de adultério, no direito das coisas a abolição dos direitos feudais ainda remanescentes. Por isso, serviu de modelo para as legislações de diversos países, a começar pela Europa, depois América Latina e em seguida Ásia e África. VideCARNIO, Henrique Garbellini et al., Curso de sociologia jurídica, São Paulo: RT, 2011, p. $89 / 91$.
} 
A alternativa subjacente a um cenário contrário, procurando encontrar na lei a resposta exacta para cada problema concreto, isto num quadro idílico da mais completa vinculação decorrente de um modelo silogístico-subsuntivo da aplicação da lei pela administração e pelos tribunais, revelaria ainda uma muito maior imperfeição da lei, observando-se que o cristalizador das previsões normativas conduziria à sua rápida desactualização e a uma visível formulação lacunar da norma legal, tal como uma estatuição fechada não responderia à multiplicidade de situações diferentes e mostraria a incapacidade de adaptação da lei ao imprevisto. Em vez de um Direito sujeito a um rápido processo de envelhecimento, a existência de normas elásticas, permite que a lei respire a atmosfera social que a envolve, adaptando-se melhor à vida através da imperfeição resultante da mobilidade do seu conteúdo. $^{89}$

Dentro dessa perspectiva contemporânea, ou se preferir pósmoderna, deu-se o advento do segundo Código Civil Brasileiro, Lei $\mathrm{n}^{\mathrm{o}}$ 10.406, de 10 de janeiro de 2002. O sistema passou de fechado para semiaberto. Ao lado das normas casuísticas outras foram introduzidas, permitindo maior liberdade ao julgador na busca da justiça acordada na realidade social. São as cláusulas gerais e os conceitos legais indeterminados.

\section{CLÁUSULAS GERAIS}

As cláusulas gerais são normas elásticas, apresentam conceitos cujos vocábulos empregados pelo legislador têm densidade semântica intencionalmente vaga e aberta, permitindo ao juiz preenchê-las com valores a serem empregados no julgamento de cada caso singular. Não oferece a solução a ser dada, de sorte não prevê a consequência jurídica, consentindo ao juiz criar soluções, vale dizer, abre-lhe à função criadora.

\footnotetext{
${ }^{89}$ Apud MAIA, Lauro Augusto Moreira. Novos paradigmas do direito civil. Curitiba: Juruá Editora, 2007, p. 63/64.
} 
São exemplos de maior interesse ao Direito das Obrigações, o art. 421 que dispõe sobre a função social do contrato, sem explicitar o que é função social; assim o art. 422 ao referir-se àboa-fé objetiva e àprobidade; o art. 1.228, $\S 1^{\circ}$, que adere ao direito de propriedade o exercício em consonância com as finalidades econômicas, sociais, etc.

\section{CONCEITOS LEGAIS INDETERMINADOS}

Os conceitos legais indeterminados, com significado paralelo às cláusulas gerais, são também normas elásticas, nas quais são introduzidos conceitos propositadamente vagos e abertos, proporcionando ao juiz preenchê-los com valores a serem empregados no julgamento de cada caso singular, com a diferença de preverem a consequência jurídica, isto é, propõem como o caso deva ser solucionado. Atiça a função criadora do juiz conquanto com menor ênfase, pois cabe a ele a escolha de valores sociais que irão presidir o caso em julgamento.

Assim, o art. 122 do Código Civil ao dispor sobre a liceidade das condições que não contrariam a ordem pública e os bons costumes; o art. 188, II, ao dispor que não constituem atos ilícitos os praticados para remover perigo iminente; art. 927, parágrafo único, que preveja as atividades de risco que conduzem à responsabilidade civil objetiva, dentre outros.

Embora nem todos civilistas façam a distinção entre essas duas figuras, preferindo a denominação genérica de cláusulas gerais, cumpre atentar à lição do casal Nelson e Rosa Nery:

[...] à primeira vista poderia haver confusão entre as cláusulas gerais e os conceitos legais indeterminados. Ocorre que em ambos há a extrema vagueza e generalidade, que tem de ser preenchida com valores pelo juiz. Quando a norma já prevê a consequência, houve determinação de conceito legal indeterminado: a solução a ser dada pelo juiz é aquela prevista previamente na norma. Ao contrário, quando a norma não prevê a consequência, dando ao juiz a oportunidade de criar a solução, dá-se ocasião de aplicação da cláusula geral: a consequência não estava prevista na norma e foi criada pelo juiz para o 
caso concreto. $\mathrm{O}$ juiz pode dar uma solução em um determinadocaso, e outra solução diferente em outro caso, aplicando a mesma cláusula geral. ${ }^{90}$

Há de se notar, todas essas expressões, standards do Direito inglês, que compõem a norma, têm como principal característica a impossibilidade de elucidação de seus conceitos sem o recurso aos mais variados parâmetros de valoração ético-social ou do costume.

De fato é assim, de modo que essas duas figuras mitigam as regras mais rígidas ao dar maior mobilidade ao Código Civil, impedindo o seu envelhecimento precoce em uma sociedade tão dinâmica como a atual. Nem por isso evitam as críticas, pois trazem certo grau de incerteza ante a característica de sua flexibilidade, uma vez que outorgam ao juiz grande margem discricionária ao preencher o seu conteúdo com valores. ${ }^{91}$

Convenha-se, a liberdade judicial não é plena, pois os valores não são aqueles próprios da convicção pessoal do magistrado, mas sim os prevalentes na consciência social, que implicam no dever ético de lealdade e cooperação nas relações intersubjetivas. Ou conforme prefere Claudio Luzzati, a aplicação de tais conceitos exige a concreção da regra ética e de costume preexistente, não significando um arbítrio às opiniões pessoais do julgador. ${ }^{92}$ Tais valores, portanto, devem ser extraídos diante do caso concreto na criteriosa análise de suas circunstâncias fáticas e jurídicas, para que se encontre a solução mais conveniente sob a ótica da justiça social..$^{93}$

${ }^{90}$ NERY JUNIOR, Nelson et al. Código civil anotado e legislação extravagante, 2 ed. São Paulo: RT, 2003, p. 141.

${ }^{91}$ NERY JUNIOR, Nelson et al., op. cit., p. 143.

92 LUZZATI, Claudio. La vaghezzadelle norme, un'analisi del linguaggiogiuridico. Milano: Giuffrè, 1990, p. 321.

93 Jorge Tosta, arribado em Humberto Theodoro Júnior e Teresa Arruda Alvim Wamber, assinala: "Assim, a atividade do juiz não pode se centrar na sua própria ideologia, na sua própria concepção de vida, nas suas crenças pessoais. Seu dever é, segundo Benjamin Cardoso, 'conformar aos standards aceitos da comunidade os mores da época.' E esses parâmetros servem, não para criar, para o caso concreto, normas diferentes da que se encontra abstratamente contida na lei, mas para buscar, dentro do ordenamento jurídico, e graças à técnica interpretativa, a regra aplicável a uma situação concreta." Para em seguida completar: "na concreção judicial [entenda-se: na interpretação-integrativa e na aplicação] de norma abertas, caracterizadas por termos vagos ou indeterminados e na aplicação de normas de tipo aberto em sentido lato, caracterizadas por juízos de oportunidade, inexiste plena liberdade judicial. O sistema jurídico como um todo contém standardse 
E não se olvide, o Direito Privado e o Direito Público estão sempre submetidos aos valores e princípios constitucionais. É a Constituição Federal que oferta a visão unitária e coerente do Direito, e que eleva essa visão do interprete para o telos do conjunto sistemático de normas. É dizer, a luz que ilumina a interpretação das normas abertas deve ser sempre a constitucional, valores outorgados e não escolhidos pelo aplicador da lei.

Bem por isso, na interpretação dessas normas abertas a jurisprudência é de grande valia na função de estabelecer o seu alcance e conteúdo, além de oferecer no correr do tempo certa segurança jurídica. É o que assegura Judith Martins-Costa: "não pretendem as cláusulas gerais dar resposta, previamente, a todos os problemas da realidade, uma vez que estas respostas são progressivamente construídas pela jurisprudência." 94

Valendo-se, pois, das cláusulas gerais e dos conceitos legais indeterminados foram introduzidos três princípios que Miguel Reale chama-os de fundantes e, em profissão de fé, adverte "não por um vício de amar o trino", que são: o da socialidade, o da eticidade e o da operabilidade.

Os princípios são diretrizes maiores do ordenamento jurídico, oferecendo às normas o seu verdadeiro sentido e alcance. Impõem a realização de valores e sua característica essencial é a indefinição em relação à situação fática, podendo aplicar-se a um número indeterminado de casos concretos. Atuam como elos de ligação entre as normas com o que garantem o ordenamento jurídico como um bloco sistemático harmonioso, consentindo a sua renovação diante das transformações sociais.

\section{$4 \quad$ PRINCÍPIO DA SOCIALIDADE}

O princípio da socialidade leva ao entendimento de que os interesses individuais, embora significativos para o ordenamento jurídico, não podem sobrelevar os interesses sociais, por serem esses informativos

Princípios gerais de Direito que orientam esse poder-dever exercido pelo juiz, a fim de encontrar-se o resultado que melhor resolva o conflito submetido à apreciação judicial." (Manual de interpretação do código civil: as normas do tipo aberto e os poderes do juiz. Rio de Janeiro: Elsevier, 2008, p. 92 e 93).

${ }^{94}$ MARTINS-COSTA, Judith. A boa-fé no direito privado. São Paulo: RT, 1999, p. 299. 
da consciência coletiva. É a lição de Cristiano Chaves Farias e Nelson Rosenvald:

$\mathrm{O}$ ordenamento jurídico concede a alguém um direito subjetivo para que satisfaça um interesse próprio, mas com a condição de que a satisfação individual não lese as expectativas coletivas que lhe rodeiam. Todo direito de agir é concedido à pessoa, para que seja realizada uma finalidade social; caso contrário, a atividade individual falecerá de legitimidade e o intuito do titular do direito será recusado pelo ordenamento. ${ }^{95}$

Busca suplantar o individualismo condenável sem cair no coletivismo, cujo engano é despersonalizar um em favor do todo.

Pondera Norberto Bobbio:

Há individualismo e individualismo. Há individualismo de tradição liberal-libertária e o individualismo de tradição democrática. O primeiro arranca o indivíduo do corpo orgânico da sociedade e o faz viver fora do regaço materno, lançando-o ao mundo desconhecido e cheio de perigos da luta pela sobrevivência, onde cada um deve se cuidar de si mesmo, em luta perpétua, exemplificada pelo hobbesianobellum ominium contra omnes [a luta do homem contra o homem]. O segundo agrupa-o a outros indivíduos semelhantes a ele, que considera seus semelhantes, para que da sua união a sociedade venha a se compor não mais como um todo orgânico do qual saiu, mas como uma associação de indivíduos livres. $\mathrm{O}$ primeiro reivindica a liberdade do indivíduo em relação à sociedade. $\mathrm{O}$ segundo reconcilia-o com a sociedade fazendo da sociedade o resultado de um acordo entre indivíduos inteligentes. $\mathrm{O}$ primeiro faz do indivíduo um protagonista absoluto, fora de qualquer vínculo social. O segundo

\footnotetext{
${ }^{95}$ FARIAS, Cristiano Chaves et al. Direito das obrigações, 4.ed. Rio de Janeiro: Lúmen Juris, 2009. p. 103.
} 
faz dele protagonista de uma nova sociedade que surge das cinzas da sociedade antiga, na qual as decisões coletivas são tomadas pelos próprios indivíduos ou por seus representantes. ${ }^{96}$

Daí a assertiva de Miguel Reale: "Se não houve a vitória do socialismo, houve o triunfo da socialidade." E prossegue, o atual Código Civil distingue-se por maior aderência à realidade contemporânea, o que leva a repensar, dentro desta ótica, os direitos e deveres dos cinco principais personagens do Direito Privado: o proprietário, o contratante, o empresário, o pai de família e o testador. ${ }^{97}$

O Código Civil refere-se ao social explicitamente em vários dispositivos. Pinçam-se alguns deles afetos à área do Direito das Obrigações: a) ao considerar abusivo o exercício de um direito (art. 187) b) ao falar diretamente na função social do contrato (art. 421); c) ao prever a probidade e a boa-fé (art. 422); d) ao estabelecer a fixação de indenização razoável pela interrupção da empreitada (art. 623); e) ao dispor que o gestor de negócio responde pelos danos causados por caso fortuito, quando realizar operações arriscadas (art. 868); f) ao inovar com a responsabilidade civil objetiva decorrente da atividade de risco(art. 926, parágrafo único), g) ao exigir que a propriedade deva ser exercida conforme as finalidades econômicas e sociais (art. 1.228, $\S 1^{\circ}$ ).

$\mathrm{Na}$ verdade, a finalidade social integra a própria natureza do Direito. Fora da sociedade não há Direito. Como já salientado, vem desde os romanos o aforismo: ubi societas, ibiius:onde está a sociedade, aí está o direito. Qualquer homem isolado, o asceta, o ermitão podem ter problema moral na relação consigo mesmo, ou problema religioso na relação com

\footnotetext{
${ }^{96}$ BOBBIO, Norberto. Teoria geral da política, tradução de Daniela BeccacciaVersiani, organizador Michelangelo Bovero. Rio de Janeiro: Campos, 2000, p. 381. Este texto distingue com clareza a questão do individualismo, embora sofra a crítica de que a sociedade é mais do que a soma do livre acordo de indivíduos inteligentes.

${ }^{97}$ REALE, Miguel. O projeto do novo código civil: situação após aprovação pelo Senado Federal, $2^{\text {a }}$ ed. São Paulo: Saraiva, 1999, p. 7. E ainda adverte Miguel Reale: "Quando entrar em vigor o novo Código Civil, a 10 de janeiro de 2003, perceber-se-á logo a diferença entre o código atual, elaborado para um País predominantemente rural, e o que foi projetado para uma sociedade, na qual prevalece o sentido da vida urbana. Haverá uma passagem do individualismo e do formalismo do primeiro para o sentido socializante do segundo, mais atento às mudanças sociais, numa composição equitativa de liberdade e igualdade." (Sentido do novo Código Civil, disponível em <HTTP://www.miguelreale.com.br/>).
} 
Deus, mas não problema jurídico. Da obra de Daniel Defoe sai o exemplo de Robison Crusoé, que viveu isolado em uma ilha do Caribe, não tinha problema jurídico, enquanto não encontrou o nativo Sexta-Feira, ao relacionar-se com ele passou a ter. É nesse contexto que o princípio da socialidade, como valor, centra as suas atenções no interesse social, entendendo o interesse individual como referência relativa, mas, repita-se, não sem lhe dar reconhecida importância.

Surge a questão: o princípio da sociedade pode colidir com os direitos fundamentais $\left(\mathrm{CF}\right.$ art. $\left.5^{\circ}\right)$ e os direitos da personalidade (CC art. 11 a 21)?

A princípio a resposta é negativa. O princípio da socialidade compromete-se com a inadiável busca de se construir uma sociedade livre, justa e solidária, pela erradicação da pobreza e da marginalização, reduzindo as desigualdades sociais e regionais $\left(\mathrm{CF}\right.$, art. $3^{\circ}$, III), plasmadas na dignidade da pessoa humana ( $\mathrm{CF}$ art. $1^{\circ}$, III), impondo rigoroso reconhecimento dos direitos fundamentais e dos direitos da personalidade, o que se constitui política humanista e humanizadora. Maria Celina Bodin de Moraes assegura que a solidariedade "é a expressão mais profunda de sociabilidade que caracteriza a pessoa humana." E conclui, na atualidade a Carta Magna exige "que nos ajudemos, mutuamente, a conservar nossa humanidade, porque a construção de uma sociedade livre, justa e solidária cabe a todos e a cada um de nós". ${ }^{98}$

Do exposto surge uma conclusão lógica, o princípio da socialidade compõe uma ordem de complementaridade com o individualismo democrático, encontrando vasto estuário nos direitos fundamentais e nos da personalidade, porquanto o que ele pretende é expurgar o individualismo liberal-libertário, evidentemente perverso, jamais despersonalizar o indivíduo em favor do todo.

Em outro enfoque é lídimo afiançar, se no caso concreto estabelecer-se a colisão proposta, prevalecem os princípios imanentes do sistema e do bloco de constitucionalidade, segundo os quais o centro do direito é a dignidade da pessoa humana e os valores que lhe são intrínsecos. É a prevalência dos direitos humanos imposição expressa da Carta Magna (art. $4^{\circ}$, II).

\footnotetext{
${ }^{98}$ MORAES, Maria Celina Bodin de. O Princípio da Solidariedade. In: Manoel Messias PEIXINHO, Isabella Franco GUERRA e Firly Nascimento FILHO (orgs.) Os Princípios da Constituição de 1988. Rio de Janeiro: Lúmen Juris, 2001. p.121.
} 
Todavia, nada no Direito é absoluto, dessa forma cumpre outra ordem de consideração que é o dever de proteção em face da coletividade. No Estado Democrático de Direito os direitos fundamentais e os direitos da personalidade não podem ser vistos pelo estreito enfoque individual, sem a indispensável proteção dos direitos integrantes da sociedade. Se eles prevalecerem, em todas as circunstâncias, será danoso à ordem pública e às liberdades alheias. Afirma com lucidez Ernani Menezes Vilhena Júnior: "Privilegiar o direito fundamental do indivíduo com grave prejuízo aos direitos fundamentais da sociedade implica inexorável ofensa a valores assegurados a todos."

Escorado na doutrina portuguesa de Dayse de Vasconcelos Mayer, o citado autor prossegue enumerando as seguintes e apertadas circunstâncias:

a) quando necessário assegurar a própria continuidade e sobrevivência da ordem jurídica;

b) se estiver em grave risco um bem jurídico que somente pode ser preservado pela restrição da liberdade;

c) quando todos e não alguns sejam abrangidos por medidas de excepcionalidade adotadas pelo Estado;

d) nas situações excepcionais e transitórias, isto é, que dure apenas enquanto permanecer a situação de perigo iminente. ${ }^{99}$

Para tanto, dois princípios são indicados, os da razoabilidade e da proporcionalidade. Sem dúvida, seus conceitos são relativos por excelência, devendo ser inferidos a partir do senso comum ou padrão médio dos indivíduos. É razoável e proporcional tudo o que o corpo social admite como solução equânime para determinada situação singular, por estar de conformidade com o interesse público. ${ }^{100}$

\footnotetext{
99 VILHENA JÚNIOR, Ernani de Menezes. Direitos fundamentais da sociedade. Revista Jurídica da Escola Superior do Ministério Público, volume 1. São Paulo: ESMP, 2012, p. 93 e 88 respectivamente.

100 PAZZAGLINI FILHO, Marino. Princípios constitucionais reguladores da administração pública. São Paulo: Atlas, 2000, p. 5.
} 


\section{$5 \quad$ PRINCÍPIO DA ETICIDADE}

Agir com eticidade significa elevar-se como pessoa humana, procedendo de maneira proba e leal na consideração de valores que exigem o respeito e o apreço aos direitos e interesses alheios.

Evidente que a eticidade evoca a ética, e essa significa o "eu" reconhecer, respeitar e reverenciar o "outro", assim entendendo: "o outro sou eu mesmo", são palavras do Apóstolo Paulo: "[...] cada um de nós somos membros um do outro" (Romanos 12, 5). Machado de Assis, no conto "O Espelho", um esboço de uma nova teoria da alma humana, coloca na boca do taciturno Jacobina, que o homem, metafisicamente falando, é uma laranja, quem perde uma das metades, perde metade da sua existência, ou seja, uma metade é o "eu" e a outra metade é o "outro".

A eticidade, contudo, não se alarga ao ponto de o Direito consagrar tudo que é moral, por comportar normas amorais, assim as que se referem ao trânsito como, por exemplo, ao estabelecer uma rua de mão única ou direcioná-la do centro para o bairro. Mas o Direito nega e rejeita a imoralidade.

Pode-se afirmar, porém, que os fundamentos da eticidade permeiam o ordenamento jurídico, incutindo-lhe os valores de justiça, solidariedade e dignidade da pessoa humana. De efeito, a eticidade é valor que abrolha do princípio da dignidade humana. Princípio abrigado praticamente em todas as legislações dos países ocidentais, como nas Constituições de Portugal e Alemanha. ${ }^{101}$

${ }^{101}$ MAIA, Lauro Augusto Moreira, op. cit., p. 34 e 35. Ainda nesta obra o autor oferece o conceito de dignidade humana: "Pico Della Mirandola teve o mérito de, ainda no século $\mathrm{XV}$, construir uma noção de dignidade humana que não estava centrada em sua fortuna, sua posição social, sua estatura funcional. A dignidade, o Homem a tinha por ser dotado de razão, construtor do seu futuro, como ser que, com liberdade, pode optar entre decisões possíveis e constituir-se num próprio ser divino." Ingo Sarlet, na sua obra Dignidade da pessoa humana e direitos fundamentais na Constituição Federal, Porto Alegre: Livraria do Advogado, 2001, define dignidade humana: "temos por dignidade da pessoa humana a qualidade intrínseca e distintiva de cada ser humano que o faz merecedor do mesmo respeito e consideração por parte do Estado e da comunidade, implicando, nesse sentido, um complexo de direitos e deveres fundamentais que assegurem a pessoa tanto contra todo e qualquer ato de cunho degradante ou desumano, como venham a lhe garantir as condições existenciais mínimas para uma vida saudável, além de propiciar e promover sua participação ativa e corresponsável nos destinos da própria existência e da vida em comunhão com os demais seres humanos." Dissertando sobre a dignidade humana na obrigação, Cristiano Chaves de Faria e Nelson Rosenvald afirmam: "Obrigação e relação obri- 
São exemplos que tocam os direitos obrigacionais: a) art. 50 do Código Civil: em caso de abuso da personalidade jurídica, o juiz poderá desprezá-la e sancionar os sócios abusivos (falta de eticidade); b) art. 110: pune-se a reserva mental (falta de eticidade)na manifestação da vontade quando da realização do negócio jurídico; c) art. 113: os negócios jurídicos devem ser interpretados conforme a boa-fé (eticidade); d) art. 167 caput: é nulo o negócio jurídicosimulado (falta de eticidade), mas são ressalvados os direitos de terceiro de boa-fé (eticidade), art. 167, $\S 2^{\circ}$; e) art. 187: considera-se ato ilícito o exercício abusivo de um direito (falta de eticidade); f) art. 421: a liberdade de contratar será exercida em razão e nos limites da função social do contrato (eticidade); g) art. 422: os contratantes são obrigados a guardar os princípios da probidade e da boa-fé (eticidade); h) art. 589, V: é ineficaz o mútuo feito a menor, salvo se ele obteve o empréstimomaliciosamente (falta de eticidade); i) art. 896: protege o portador de boa-fé (eticidade) contra a reivindicação de título de crédito; j) art. 1.258 e parágrafo único: aquele que constrói em seu solo e invade parcialmente solo alheio, se agiu de boa-fé (eticidade) adquire a parte do solo invadido, indenizando o valor da área perdida e a desvalorização da área remanescente, mas se agiu de má-fé (falta de eticidade) a indenização será em décuplo.

Dos exemplos colacionados muitos são comuns aos princípios da socialidade e da eticidade que se entrelaçam, um completando o outro, de modo são duas veredas aplainadas por valores similares. Tanto assim, que o princípio da socialidade nasce de um dever ético, que obriga o titular de um direito subjetivo harmonizar o seu interesse ao interesse social. De outra face, a eticidade, tendo por proposta o comprometimento do Direito com ideais de alta estima de uma comunidade, está intimamente ligada ao paradigma socialidade, pois somente assim poderá ter um significado realmente edificante. ${ }^{102}$ É a sabedoria nata dos africanos, que usam

gacional. Estrutura e função. Autonomia privada, boa-fé e função social. Indivíduo e pessoa. Patrimônio e existência. Solidão e solidariedade. A dignidade da pessoa humana se coloca em todos esses momentos. Em seu perfil ativo, convida os indivíduos isolados ao contrato social e ao entabulamento da obrigação, garantindo condições para o pleno desenvolvimento da liberdade humana. A dignidade, porém, age em outra vertente. $\mathrm{O}$ homem se converte em pessoa no mundo solidário das relações obrigacionais. Qualquer sociedade só se afirma em cooperação, traduzida esta pela boa-fé e função social no reino dos negócios jurídicos." (Direitos das obrigações, 4.ed. Rio de Janeiro: Lúmen Juris, 2009, p. 8).

102 MAIA, Lauro Augusto Moreira; op. cit., p. 30. 
a palavra ubuntu a significar: "eu sou o que sou porque pertenço à comunidade", ou "eu sou o que sou através de você, e você é você através de mim", portanto "todos precisamos uns dos outros; somos interdependentes".

O certo é que esses dois princípios trouxeram ao Código Civil uma nova dinâmica, ou se constituem em paradigmas que rompem com o formalismo técnico-jurídico próprio do individualismo que antecede a metade do século passado, ampliando as normas inscritas na Lei de Introdução às Normas do Direito Brasileiro (até 2010 chamada Lei de Introdução do Código Civil). $\mathrm{O}$ art. $4^{\circ}$ ao atribuir maior valoração à analogia, aos costumes e aos princípios gerais do Direito. E o art. $5^{\circ}$ em que o juiz deverá atender aos fins sociais e às exigências do bem comum. De efeito, ao juiz é assegurada a necessária liberdade de distribuir, em cada caso singular, o julgamento mais equânime, o que conduz ao justo anseio dos jurisdicionados.

Cabe uma ressalva, o Código Civil de Reale acrescentou, com relação ao Código Civil de Bevilaqua, novos artigos, nos quais da boa-fé ou da má-fé decorrem consequências jurídicas, ampliando e melhorando o princípio da eticidade, logo não lhe é exclusivo. De efeito, são exemplos de eticidade no Código Civil revogado, dentre outros, os artigos 510, 513 a $515,550,551,612,613,616,933$, parágrafo único, 968, 1.002, $1.072,1.073,1.318$ e $1 ; 321,1.443$.

\section{$6 \quad$ PRINCÍPIO DA OPERABILIDADE}

O princípio da operabilidade foi inspirado no Direito alemão, e segundo Miguel Reale: "o Direito é feito para ser executado; Direito que não se executa - já dizia Jhering na sua imaginação criadora - é chama que não aquece, luz que não ilumina." ${ }^{103}$ Lembra a parábola da lâmpada: "Por acaso toma-se uma lanterna para colocar debaixo do alqueire ou do leito? Por acaso não é para colocar sobre o candelabro" (Mc. 8, 21). Explica Norberto Bobbio: "Finalmente, descendo do plano ideal ao plano real, uma coisa é falar dos direitos do homem, direitos sempre novos e

${ }^{103}$ REALE, Miguel, op. cit., p. 10. 
cada vez mais extensos, e justificá-los com argumentos convincentes; outra coisa é garantir-lhes uma proteção efetiva". ${ }^{104}$

Proteção efetiva significa que as novas normas têm mais clareza redacional, tornando-as de mais fácil operabilidade no caso concreto, de modo a estabelecer soluções normativas que facilitem sua interpretação pelo operador do Direito, isto é, o acesso da vida dos textos para a vida prática. Para tanto, o Código vigente abandonou a redação esmerada, até clássica do Código revogado, mormente depois da revisão de Ruy Barbosa. Sua linguagem é menos rebuscada, mais inteligível, ao alcance do jurisdicionado e de tal modo devem ser dirigidas as decisões judiciais.

Supera também as dúvidas remanescentes do sistema passado, por meio de metódica análise da jurisprudência. Exemplo marcante é o art. 330 do Código Civil, que abraçou a jurisprudência ao introduzi-la em preceito escrito.

O mesmo se deu com a prescrição e a decadência. Afastaram as dúvidas 205 e suscitadas pelas teorias estéreis que até então proliferaram, pouco esclarecendo. Ficou nítida a diferença entre ambas. A orientação geral é a seguinte: os casos de prescrição estão contidos nos arts. 206, da Parte Geral. Em todos os demais casos, em regra, o prazo extintivo é decadencial.

Ademais, cabe uma nova leitura do direito processual. Há de convir, o direito material sobreleva o instrumental. Quem ingressa em juízo visa à efetivação, por meio do direito subjetivo, o que lhe confere o direito objetivo, não para discutir normas puramente processuais. São cada vez mais arcaicas e odiosas as decisões privilegiadamente processuais, quando a forma supera o conteúdo. Direito material e direito instrumental devem manter um diálogo permanente de maneira que o segundo facilite com normas claras e de fácil operabilidade o primeiro, inclusive preocupando-se com as decisões em tempo útil, desburocratizando o processo que deve contemplar a verdade material.

De todo o expendido a conclusão é dual. Por um lado, indica que o Livro do Direito das Obrigações e os demais Livros do Código Civil devem ser lidos na consideração dos três princípios expostos, para a boa e cabal interpretação de suas normas dentro de novos paradigmas que os afetam diretamente, tornando-os atuais e efetivos em uma sociedade

${ }^{104}$ BOBBIO, Norberto. A era dos direitos, tradução de Nelson Coutinho. Rio de Janeiro: Campus, 1992, p. 63. 
que experimenta mudanças constantes ante o dinamismo que caracteriza a vida contemporânea. Por outro lado, as decisões judiciais não podem mais se contentar com a verdade formal, chamada por alguns de segurança jurídica, a nova leitura está a exigir a busca da verdade material, pois só assim se restabelece a paz social quebrada pelo conflito de interesses. É um basta à perfídia "do faz de conta" de que a justiça foi distribuída, fazendo crer que o Poder Judiciário apenas dirime conflitos de interesses.

\section{CONSIDERAÇÕES FINAIS}

Assim entendendo há de se admitir, o Código Civil de Reale é principiológico, um sistema semiaberto, pois ao lado das normas casuísticas perfilam as cláusulas gerais e os conceitos legais indeterminados, dando flexibilidade ao sistema.

Quanto ao Direito das Obrigações rompe com o individualismo da legislação passada, não mais aceita a sua plenitude hermenêutica ao conduzir à analogia e aos princípios gerais, prevalecendo, a todo instante, a valoração das consequências da cláusula rebus sic stantibus, a fim de buscar o equilíbrio econômico do contrato.

Enfim, o Direito das Obrigações passa ser considerado dentro da base ética, o que é sensível e benfazejo progresso, de há muito esperado é trabalhado pela doutrina e jurisprudência que ultrapassaram, em muitos casos, a lei então posta ante o seu envelhecimento com o trepidar do tempo.

Poderia, no entanto, ser mais arrojado nas suas regras, não apenas atendo a consolidar modelos jurídicos já recepcionados, ao mesmo tempo em que se eleva na humildade de deixar ao legislador a empreitada de, no futuro, aduzir novas leis para complementá-lo.

\section{REFERÊNCIAS BIBLIOGRÁFICAS}

BOBBIO, Norberto. Teoria geral da política. Trad. Daniela BeccacciaVersiani. Rio de Janeiro: Campus, 2000.

A era dos direitos.Trad. Nelson Coutinho. Rio de Janeiro: Campus. 1992. 
FARIAS, Cristiano Chaves et al. Direito das obrigações. 4.ed. Rio de Janeiro: Lúmen Juris, 2009.

LUZZATI, Claudio. La vaghezza dele norme, un'analisidellinguaggiogiuridico. Milano: Giuffrè, 1990.

MAIA, Lauro Augusto Moreira. Novos paradigmas do direito civil. Curitiba: Juruá, 2007.

MARTINS-COSTA, Judith. A boa-fé no direito privado. São Paulo: Revista dos Tribunais, 1999.

MORAES, Maria CelinaBodinde. O Princípio da Solidariedade. In: Manoel Messias PEIXINHO, Isabella Franco GUERRA e Firly Nascimento FILHO (orgs.) Os Princípios da Constituição de 1988. Rio de Janeiro: Lúmen Juris, 2001.

NERY JUNIOR, Nelson, et.al. Código civil anotado e legislação extravagante. 2.ed. São Paulo: Revista dos Tribunais, 2003.

PAZZAGLINI FILHO, Mariano. Princípios constitucionais reguladores da administração pública. São Paulo: Atlas, 2000.

REALE, Miguel. O projeto do novo código civil: situação após aprovação pelo Senado Federal. 2.ed. São Paulo: Saraiva, 1999.

VILHENA JÚNIOR, Ernani de Menezes. Direitos fundamentais da sociedade. Revista Jurídica da Escola Superior do Ministério Público. vol. 1. São Paulo: ESMP, 2012. 